\title{
PACAP-38 Enhances Excitatory Synaptic Transmission in the Rat Hippocampal CA1 Region
}

\author{
Marisa Roberto ${ }^{1}$ and Marcello Brunelli ${ }^{1,2}$ \\ ${ }^{1}$ Department of Physiology and Biochemistry, Institute Giuseppe Moruzzi, University of Pisa, Pisa, Italy
}

\begin{abstract}
Specific receptors for pituitary adenylate cyclase-activating polypeptide (PACAP), a novel peptide with neuroregulatory and neurotrophic functions, have been identified recently in different brain regions, including the hippocampus. In this study, we examined the effects of PACAP-38 on the excitatory postsynaptic field potentials (fEPSPs) evoked at the Schaffer collateral-CA1 synapses. Brief bath application of PACAP-38 (0.05 $\mathrm{nM}$ ) induced a long-lasting facilitation of the basal transmission. Enhancement of this response was occluded in part by previous high-frequency-induced long-term potentiation (LTP). PACAP-38 did not significantly alter the paired-pulse facilitation (PPF). PACAP-38 has been shown to have a presynaptic effect on the septohippocampal cholinergic terminals, which results in an increase in basal acetylcholine (ACh) release. To assess whether the PACAP-38 enhancement of CA1 synapses was related to the activation of the cholinergic system we examined the effect of this peptide in the presence of atropine, a muscarinic receptor antagonist. The enhancement of the fEPSPs by PACAP-38 was blocked by bath application of atropine. These results show that PACAP-38 induces facilitation of hippocampal synaptic transmission through activation of the cholinergic system via the muscarinic receptors.
\end{abstract}

Pituitary adenylate cyclase-activating polypeptide (PACAP) is a new member of a neuropeptide family that includes vasoactive intestinal peptide (VIP), glucagon, secretin, and growth hormone, and whose members are thought to play an important role in neuronal function (Miyata et al. 1989; Arimura 1998). PACAP has been isolated from the ovine hypothalamus on the basis of its ability to stimulate adenylate cyclase in rat anterior pituitary cells (Miyata et al. 1989) and it is present in the central nervous system (CNS) and in a variety of peripheral tissues (Masuo et al. 1992; Arimura and Shioda 1995; Shioda et al. 1997). Two distinct forms of this neuropeptide, PACAP-38 and PACAP-27, with 38 or 27 amino acids, respectively, have been characterized (Arimura and Shioda 1995). PACAP-38 and PACAP-27 possess similar biological activity (Miyata et al. 1990). PACAP38 is the prevailing form in mammalian tissues (Arimura 1992). The amino-acid sequence of PACAP-38 is well-preserved in different species and is identical in sheep, rats, and humans (Arimura 1992). Two types of high-affinity PACAP receptors have been identified: The PACAP type-I receptor (PACAPRI), which specifically binds PACAP-38 and PACAP-27 with higher affinity than it binds VIP; and the PACAP type-II receptor (PACAPRII), which has high homology with the VIP receptor and binds PACAP-38, PACAP-27, and VIP with the same high affinity (Arimura 1992; Sokolov and Kleschevnikov 1995). PACAPRI is mainly distributed in the CNS, including the septum, hippocampus, cerebellar

${ }^{2}$ Corresponding author.

E-MAIL marbru@dfb.unipi.it; FAX 39-50-552183.

Article and publication are at www.learnmem.org/cgi/doi/ $10.1101 / \mathrm{lm} .34200$. cortex, amygdala, nucleus accumbens, hypothalamus, and the entorhinal cortices (Masuo et al. 1992,1993) and it is positively coupled to adenylate cyclase and phospholipase C, whereas PACAPRII is highly expressed in thalamus, hippocampus, and in various hypothalamic nuclei (Masuo et al. 1992,1993) and is linked only to adenylate cyclase (Arimura 1992; Spengler et al. 1993; Leech et al. 1995). These second messenger pathways have been shown to underlie certain forms of synaptic plasticity (Greengard et al. 1991; Siegelbaum and Kandel 1991; Wang et al. 1991; Malenka and Nicoll 1999), suggesting that PACAP-38 may regulate longterm synaptic changes. It is interesting that PACAP is homologous with a peptide encoded by the Drosopbila memory gene amnesiac, which has been shown to be involved in synaptic transmission and memory storage (Feany and Quinn 1995; Zhong and Pena 1995). Masuo et al. (1993) have shown that PACAP-38, applied via a microinjection cannula, enhances in a dose-dependent manner, the spontaneous release of acetylcholine (ACh) from the septal cholinergic fibers in the dorsal hippocampus in a dose-dependent manner. They reported that PACAP-38 was more potent than PACAP-27 in stimulating the release of ACh (Masuo et al. 1993). This release of ACh was highly calcium dependent, suggesting that PACAP-38 works via a presynaptic mechanism (Matthews et al. 1987; Margiotta and Pardi 1995). PACAP-38, acting through type-I receptors, enhances the ACh sensitivity of ciliary ganglionic neurons by a cAMPdependent mechanism (Matthews et al. 1987). The hippocampus receives abundant extrinsic cholinergic innervation from the medial septal area (Frotscher and Léranth 1985; Matthews et al. 1987), and the septohippocampal choliner-

LEARNING \& MEMORY 7:303-311 @ 2000 by Cold Spring Harbor Laboratory Press ISSN1072-0502/00 \$5.00

$$
\begin{aligned}
& \begin{array}{lllllllllllllllllllllllllll} 
& E & A & R & N & I & N & G & \mathbf{Z} & M & E & M & O & R & Y
\end{array} \\
& \text { www.learnmem.org }
\end{aligned}
$$


gic pathway has been suggested to have an important role in learning and memory (Valentino and Dingledine 1981; Krnjevic and Ropert 1982; Hepler et. al. 1985; Madison et al. 1987; Brandner and Schenk 1998). Together, these data suggest that PACAP-38 may influence synaptic plasticity through its actions on the cholinergic system in the hippocampus. Long-term potentiation (LTP), which is a long-lasting, use-dependent increase in the efficacy of synaptic transmission, is thought to underlie the fundamental properties of memory (Bliss and Lomo 1973; Chen and Tonegawa 1997; Abel and Kandel 1998). It has been shown that muscarinic receptor stimulation can induce LTP at the Schaffer collateral-CA1 synapses. This muscarinic-induced LTP (LTPm) resembles LTP produced by tetanic stimulation (Marchi and Raitieri 1989; Blitzer et al. 1990; Markram and Segal 1990; Shimoshige et al. 1997). With this background, the aim of this study was to investigate the effect of PACAP38 in the hippocampus, the brain region that has been long known to be essential for learning and memory (Abel and Kandel 1998). In particular, we studied the effect of PACAP38 on rat basal- CA1 hippocampal synaptic transmission and on activity-dependent changes of synaptic strength during LTP to determine if these effects are mediated through actions on ACh release.

\section{RESULTS}

\section{PACAP-38-Induced Enhancement of CA1 Excitatory Postsynaptic Field Potentials (fEPSPs)}

A test stimulus of Schaffer collateral fibers evoked a fEPSP in the stratum radiatum of the CA1 region. Bath application of $0.05 \mathrm{nM}$ PACAP-38 for $10 \mathrm{~min}$ induced a long-lasting enhancement of this synaptic response. This potentiation of the fEPSP persisted following washout of PACAP-38 (Fig. 1A). In all slices analyzed $(n=8)$, after $10 \mathrm{~min}$ of PACAP-38 application, the mean fEPSP amplitude and the fEPSP slope increased significantly to $148.1 \pm 13.1 \%$ and $150.0 \pm 11.2 \%$, respectively $(P<0.001)$. The enhancement reached maximum levels $25 \mathrm{~min}$ after the washout of the peptide at which time the fEPSP amplitude and initial slope were $175.0 \pm 11.1 \%$ and $174.2 \pm 11.2 \%$, respectively $(P<0.001)$. In the graph, we show that the PACAP-38-induced poten-

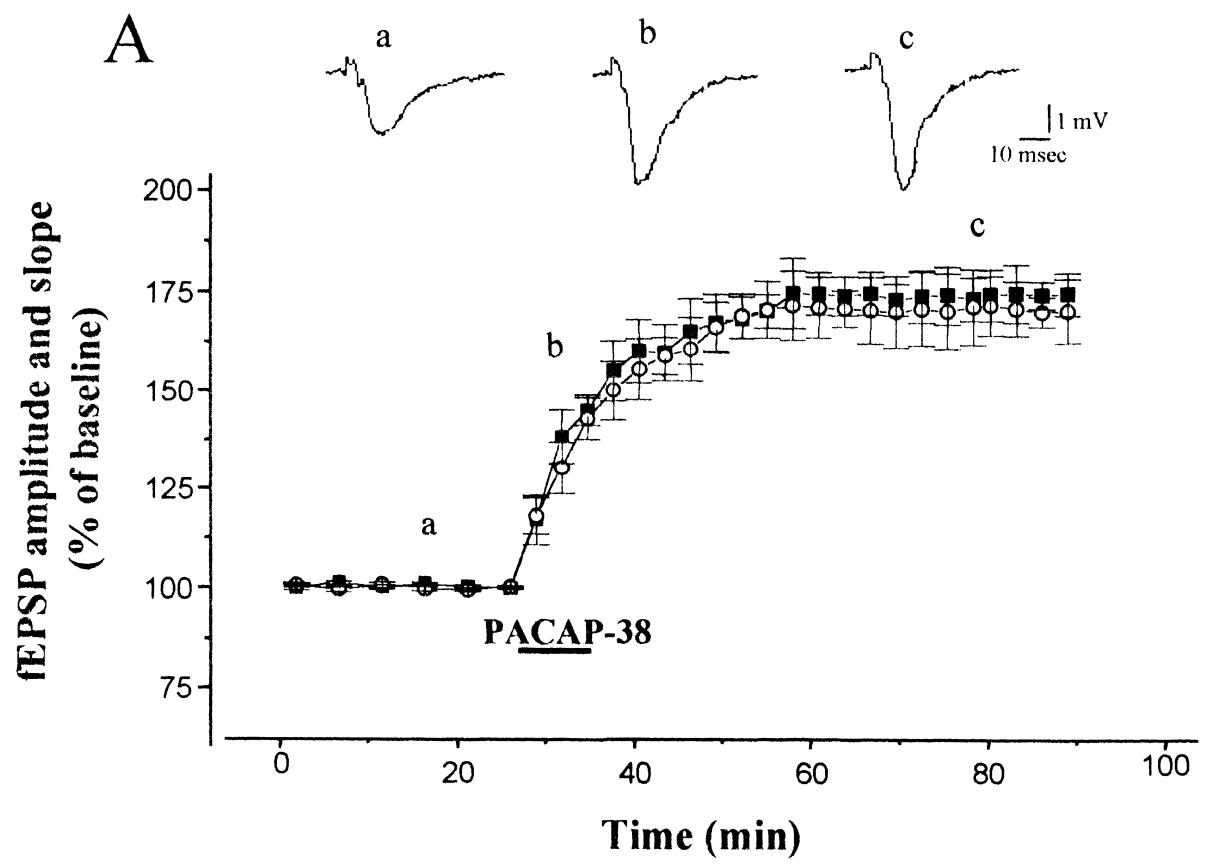

B

Figure 1 Pituitary adenylate cyclase-activating polypeptide-38 (PACAP-38) enhances excitatory postsynaptic field potentials (fEPSPs) in the CA1 region. (A) The graph shows data obtained from eight slices in which $0.05 \mathrm{nM}$ PACAP-38, applied for 10 min, increased the mean fEPSP amplitude (solid square) and slope (open circle) from the baseline values to $148.1 \pm 13.1 \%$ and $150.0 \pm 11.2 \%$, respectively $(P<0.001)$. The enhancement of fEPSP amplitude and slope reached its maximum value during the washout $(25 \mathrm{~min}, 175.0 \pm 11.1 \%$ and $174.2 \pm 11.2 \%$, respectively) and persisted at that level for the remainder of the recording period. The mean \pm the standard error of the mean of the fEPSP amplitude and slope are plotted as the percent change over the baseline values. The traces represent the CA1 synaptic responses to Schaffer collateral-commissural stimulation (average of five single sweeps) obtained from a slice recorded before (a), during (b), and after bath application of $0.05 \mathrm{nM}$ PACAP-38 (c). (B) Paired stimuli using a 40-msec interpulse interval were delivered, the ratio of the second fEPSP slope to the first fEPSP slope ( $\mathrm{fEPSP}_{2} / \mathrm{fEPSP}_{1}$ ) was determined, and the ratios were averaged and plotted. For clarity, the histograms show only the mean paired-pulse facilitation (PPF) ratio at the same times as those shown in graph $(A)$ : Baseline mean $\mathrm{fEPSP}_{2} / \mathrm{fEPSP}_{1}$ slope ratio measured before the PACAP-38 application ( $\mathrm{a}, 1.65 \pm 0.01)$, during the PACAP-38 bath application $(\mathrm{b}, 1.55 \pm 0.05, n=8 ; P>0.05)$, and during the washout $(\mathrm{c}, 1.61 \pm 0.02)$.

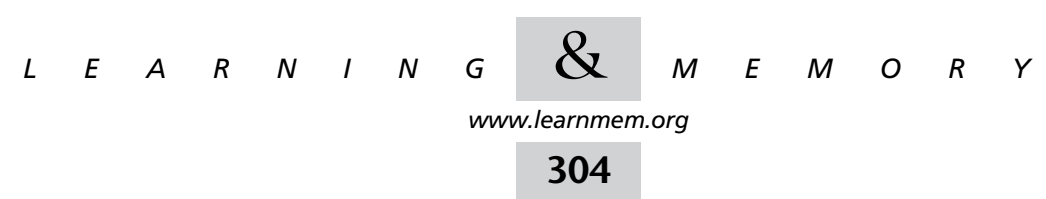


tiation lasted for $60 \mathrm{~min}$, but the responses were potentiated for the entire recording period $(180 \mathrm{~min})$ after the washout of the peptide (not shown). In the concentrationresponse study, the application of lower concentrations of PACAP-38 (0.025 nM and $0.001 \mathrm{nM})$ did not cause any significant increase in the synaptic response (Fig. 2). To determine whether PACAP-38 action might affect short-term changes in synaptic strength, we studied the paired-pulse facilitation (PPF) before, during, and after PACAP-38 application. We determined the ratio of the slope of the second fEPSP to the slope of the first fEPSP (fEPSP $2 / \mathrm{fEPSP}_{1} \mathrm{PPF}$ ratio), averaged over all the slices and plotted at the same times as in Figure 1A ( $a, b, c$; Fig. 1B). PACAP-38 increased the slope of the first and the second fEPSPs in parallel. Thus in the same slices there was no significant change in PPF as determined by fEPSP $_{2} /$ fEPSP $_{1}$. The mean value of fEPSP $_{2} /$ fEPSP $_{1}$ during the application of PACAP-38 was $1.55 \pm 0.05$, compared to the control value $(1.65 \pm 0.01$, $P>0.05)$.

\section{PACAP-38 Effect on CA1 fEPSPs Following LTP Saturation by Repeated Tetani}

The PACAP-38-induced enhancement of the synaptic strength at the Schaffer collateral-CA1 synapses was longlasting (Fig. 1A). This long-lasting increase in the efficacy of synaptic transmission suggested that common mechanisms lie downstream from both the PACAP-38 action and the expression of LTP. To verify these putative similarities, we examined the effect of PACAP-38 following tetanic LTP satu-

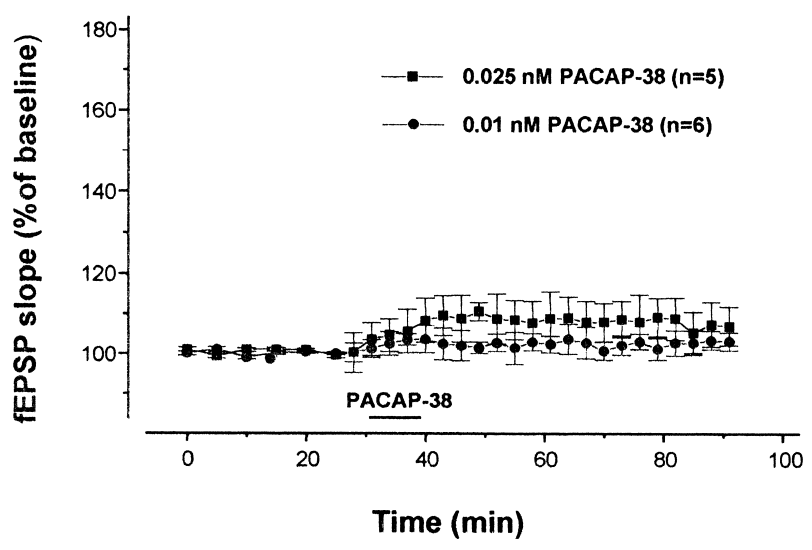

Figure 2 Minimal effective concentration of pituitary adenylate cyclase-activating polypeptide-38 (PACAP-38). Bath application of $0.025 \mathrm{nM}$ PACAP-38 and 0.001 nM PACAP-38 did not alter the synaptic response significantly compared to the baseline values. The mean slopes of the excitatory postsynaptic field potentials (fEPSP) at $10 \mathrm{~min}$ after application of $0.025 \mathrm{nM}$ PACAP-38 (solid square) and $0.001 \mathrm{nM}$ PACAP-38 (solid circle) were $108.32 \pm 5.8 \%$ and $104.32 \pm 3.5 \%$, respectively, neither of which was significantly different from the baseline value $(P>0.05)$. The mean \pm the standard error of the mean of the slope of the excitatory postsynaptic field potentials is plotted as the percent change over the baseline value. ration by sequential deliveries of high frequency stimulation (HFS). LTP expression was detected by measuring the fEPSP slope, which increased significantly to $157.0 \pm 6.9 \%$ of the pretetanus value $(n=8, P<0.001) 20$ min after the delivery of the last HFS and immediately before the application of PACAP-38 (Fig. 3A). PACAP-38, further, significantly enhanced the fEPSP slope to $203.7 \pm 13.1 \%(n=8, P<0.001)$. Under this condition of LTP saturation, the PACAP-38-induced enhancement which lasted for a shorter period. However, within $30 \mathrm{~min}$ after washout of the peptide, the PACAP-38-induced enhancement of the fEPSP slope returned to preapplication levels (157.4 $\pm 7.2 \%$; Fig. 3A). Figure $3 \mathrm{~B}$ shows that LTP was accompanied by a significant decrease in the average PPF ratio. The baseline PPF ratio over the control period before the HFS was $1.98 \pm 0.06$ $(n=8)$. It declined to $1.83 \pm 0.01(P<0.05)$ after the final HFS and remained at that level throughout the recording period before the application of PACAP-38. PACAP-38 induced a slight decline in the PPF ratio to $1.74 \pm 0.08$ $(P>0.05)$, with recovery on washout $(1.82 \pm 0.06)$.

\section{Atropine Block of PACAP-38-Induced Enhancement of CA1 fEPSPs}

It has been shown that low doses of PACAP-38 increase the spontaneous basal release of ACh from the septal cholinergic terminals (Masuo et al. 1993). In addition, it has been shown that bath application of submicromolar concentrations of carbachol $(\mathrm{CCh})$ produced a gradually developing, long-lasting increase in the CA1 fEPSP, called muscarinic long-term potentiation (LTPm), that is blocked by atropine (Madison et al. 1987; Miyata et al. 1989; Blitzer et al. 1990; Auerbach and Segal 1994; Liu and Madsen 1997; Shimoshine et al. 1997). Therefore, to assess the contribution of cholinergic receptors to the facilitation induced by PACAP-38 of the fEPSP described above, we repeated the experiments in the presence of atropine. Atropine $(1 \mu \mathrm{M})$ alone caused a small but nonsignificant reduction of fEPSP amplitude and initial slope (not shown) during $20 \mathrm{~min}$ of application, with recovery on washout. Atropine markedly blocked the fEPSP increase produced by 0.05 nM PACAP-38 in all nine of the slices that were tested $(148.1 \pm 13.1 \%$ and $150.0 \pm 11.2 \%$ fEPSP amplitude and slope facilitation, respectively, induced by PACAP-38 alone, and $115.7 \pm 5.7 \%$ and $110.0 \pm 5.5 \%$ fEPSP amplitude and slope facilitation, respectively, induced by PACAP-38 in the presence of atropine, $P<0.05$; Fig. $4 \mathrm{~A}$ ). Figure $4 \mathrm{~B}$ shows the mean $\mathrm{PPF}$ ratio at the same times marked in Fig. 4A. PPF did not change during atropine application. Mean baseline PPF ratio of fEPSP slope was $1.88 \pm 0.02$ and the PPF ratio of fEPSP measured after $15 \mathrm{~min}$ of atropine perfusion was $1.9 \pm 0.03$, respectively $(P>0.05)$. The mean PPF ratio decreased slightly to $1.78 \pm 0.05$ during the application of PACAP-38 ( $P>0.05$; Fig. 4B). 


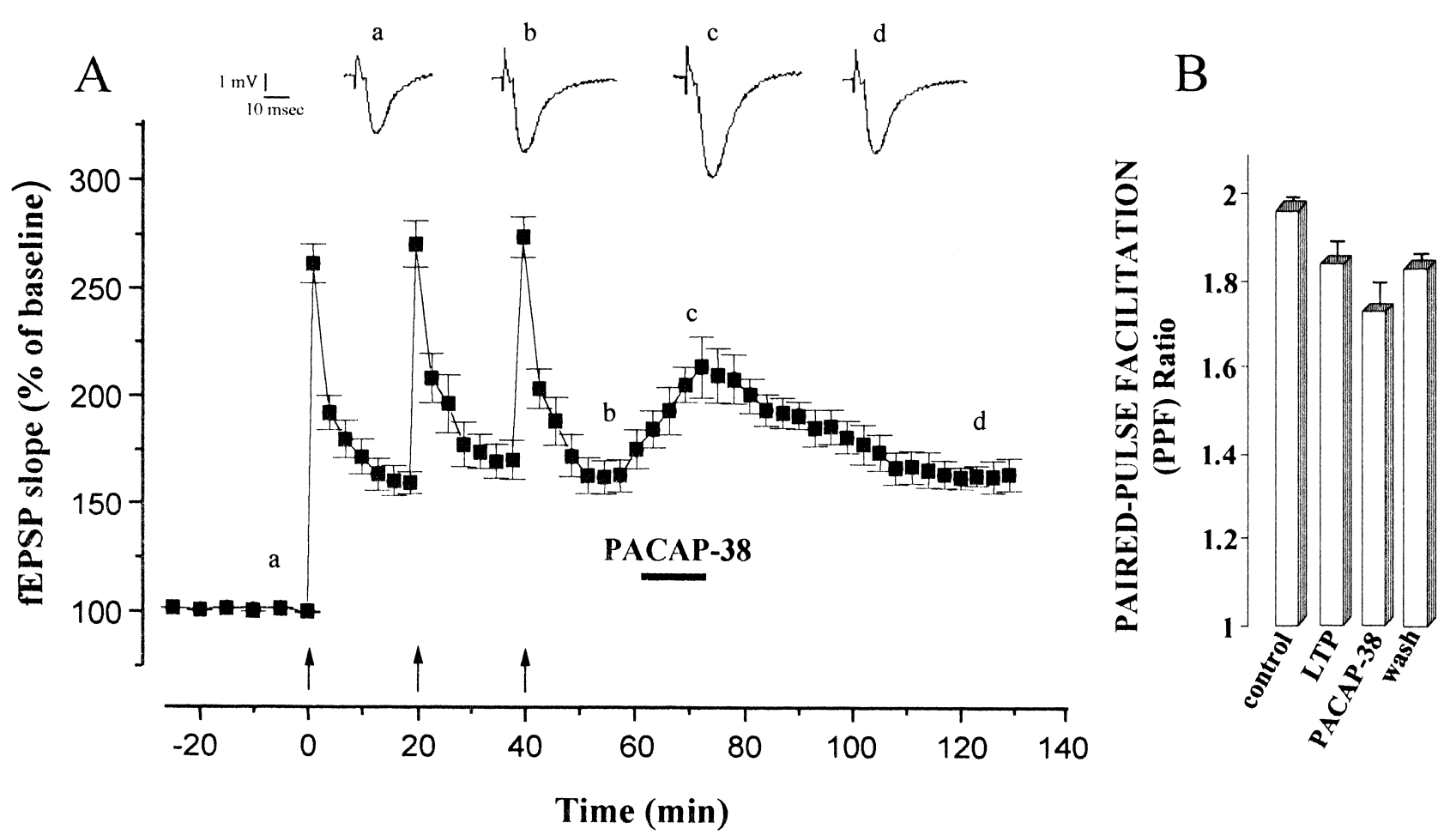

Figure 3 Further pituitary adenylate cyclase-activating polypeptide-38 (PACAP-38)-induced enhancement of CA1 excitatory postsynaptic field potentials (fEPSPs) following long-term potentiation (LTP) saturation by repeated tetani. (A) The graphs represent pooled data from eight slices. The tetanic LTP was saturated by successive trains of high-frequency stimulation (HFS; $100 \mathrm{~Hz}$, for $1 \mathrm{sec}$, three trains at 20 min intervals); the arrows denote the points at which the HFS was delivered. After LTP saturation, the mean fEPSP slope was $157 \pm 6.9 \%$ of pretetanus value $(n=8, P<0.001)$. Bath application of $0.05 \mathrm{nM} \mathrm{PACAP}-38$ for $10 \mathrm{~min}$ further enhanced the fEPSP slope to $203.7 \pm 13.1 \%$ $(n=8, P<0.001)$. Potentiation caused by PACAP-38 in this condition was not long lasting and the mean fEPSP slope returned to the preapplication value on washout $(157.4 \pm 7.2 \%)$. Each point plotted is the average of five traces, except for the first point after each HFS, which represents PTP and is the average of a single trace from each experiment. Insets: Representative records of fEPSP obtained from a slice at the times marked on the graph (baseline fEPSP [a]; after tetanic LTP saturation and immediately before the PACAP-38 bath application [b]; during [c], and after [d] the PACAP-38 perfusion). (B) mean paired-pulse facilitation (PPF) ratio taken in the same slices as in $A$ at the same times marked in the graph $(\mathrm{a}, \mathrm{b}, \mathrm{c}, \mathrm{d})$. After LTP was saturated, $0.05 \mathrm{nM}$ PACAP-38 did not significantly alter the mean PPF ratio (1.83 \pm 0.05 vs. $1.74 \pm 0.08, P>0.05)$.

\section{Atropine Block of PACAP-38-Induced Enhancement of CA1 fEPSPs Following LTP Saturation by Repeated Tetani}

To assess whether the muscarinic receptors were also involved in the additive enhancing effects of PACAP-38 and LTP of fEPSP, we performed a series of experiments using atropine. In all the slices analyzed $(n=12)$, atropine, applied after LTP saturation by repeated tetani, completely blocked the enhancement induced by PACAP-38. Figure 5A shows that the increase in the fEPSP slope after LTP saturation was $168.3 \pm 12.4 \%$. The application of atropine did not induce a significant change in the magnitude of the LTP expression (at $15 \mathrm{~min}$ after atropine perfusion, the mean fEPSP slope was $165.4 \pm 11.6 \%, P>0.05$ ), but it prevented the PACAP-38 facilitation (at $10 \mathrm{~min}$ of coapplication the mean fEPSP slope was $166.4 \pm 11.2 \%, P>0.05$ ). Atropine did not alter the PPF ratio of the fEPSP slope (Fig. $4 \mathrm{~B}$ ). Similarly, PACAP-38 induced a slight decrease of the PPF ratio from $1.89 \pm 0.05$ to $1.81 \pm 0.08(P>0.05)$ with recovery during washout of the peptide (Fig. 5B).

\section{Discussion}

Studies in the last few years indicate that neuropeptides can modulate a wide variety of synapses. The main finding of this study is that the peptide, PACAP-38 (0.05 nM), enhanced excitatory synaptic responses in the CA1 region during baseline synaptic transmission and during activitydependent alteration of synaptic transmission (i.e., LTP). We also found evidence that atropine blocked the PACAP38-induced enhancement of the CA1 fEPSP responses, which indicates that PACAP-38 action is mediated by the cholinergic system. In contrast to our results, Kondo et al. (1997) previously reported that a higher concentration of PACAP-38 $(1 \mu \mathrm{M})$ induced a long-lasting depression, rather than a potentiation, of transmission at hippocampal CA1 synapses. LTP is induced by low-frequency-induced long-

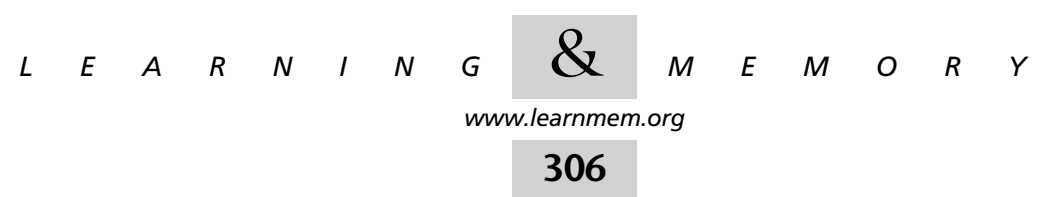



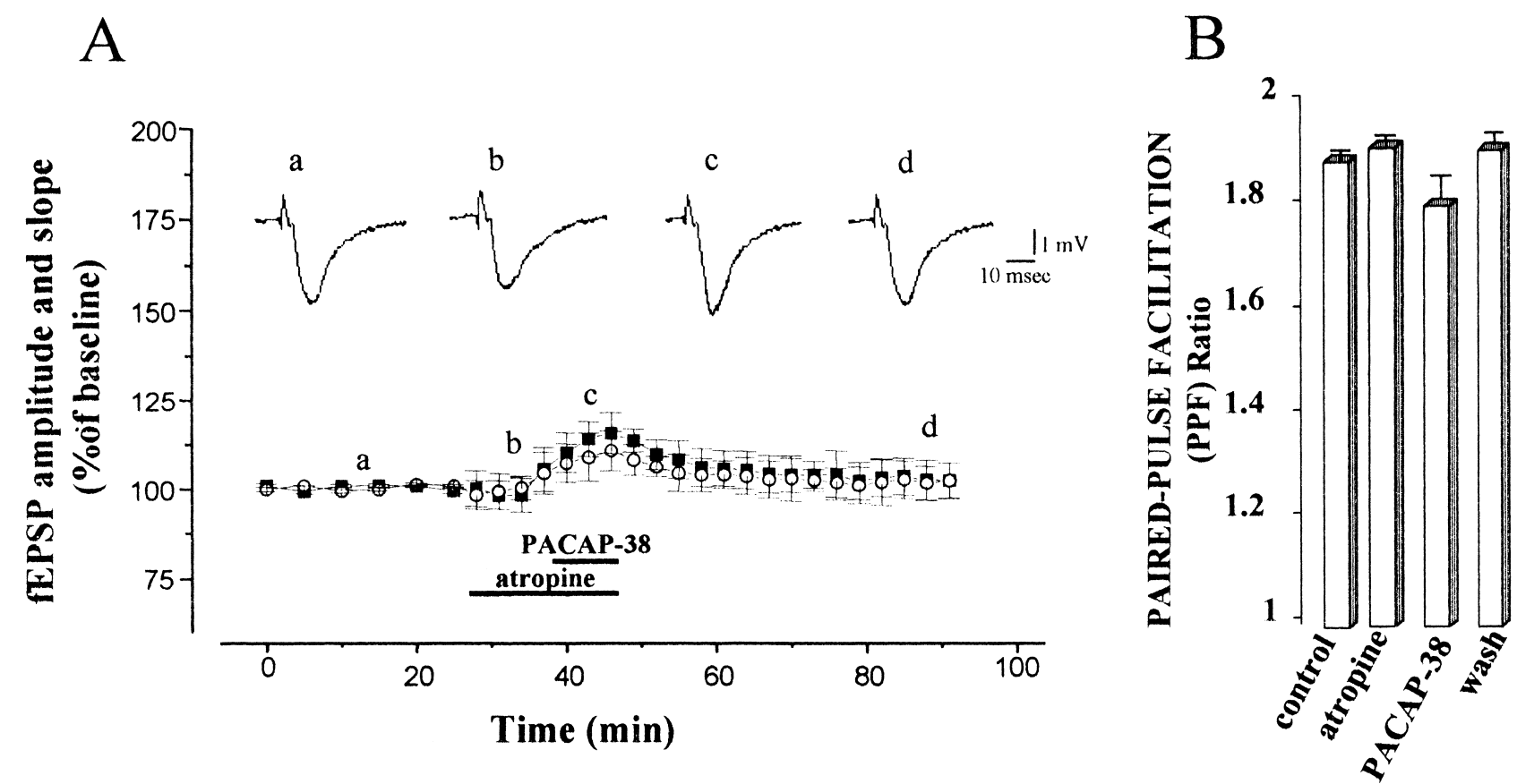

Figure 4 Blockade of atropine of pituitary adenylate cyclase-activating polypeptide-38 (PACAP-38)-induced enhancement of CA1 excitatory postsynaptic field potentials (fEPSP). (A) Atropine $(1 \mu \mathrm{M})$, a muscarinic cholinergic receptor antagonist, was applied to the slices 10-15 min before and $10 \mathrm{~min}$ simultaneously with $0.05 \mathrm{nM}$ PACAP-38 to examine whether muscarinic receptors mediate the PACAP-38-induced enhancement of excitatory post-synaptic field potentials (fEPSP). Atropine significantly blocked the PACAP-38-induced enhancement of fEPSP amplitude and slope. PACAP-38 induced only a small and transient facilitation of the fEPSP. At 10 min after PACAP-38 bath application, the percentage change in fEPSP amplitude and initial slope was $110.78 \pm 6.30 \%$ and $107.42 \pm 3.0 \%$, respectively, $(n=9$, $P>0.05)$ in the slices treated with atropine plus PACAP-38, which was smaller than the percentage change in the slices treated with PACAP-38 alone $(148.10 \pm 13.14 \%$ and $150.0 \pm 11.2 \%$, respectively, $n=8, P<0.001)$. The traces shown in the top part of the figure represent the fEPSP (average of five single sweeps) obtained from a slice recorded during the control period (a), during the application of atropine (b), during coapplication of atropine and PACAP-38 (c $>$ ) and on washout (d). (B) The mean control paired-pulse facilitation (PPF) ratio of the fEPSP slope was $1.88 \pm 0.02$ and the mean PPF ratio measured after 15 min of atropine perfusion was $1.9 \pm 0.03(P>0.05)$. The PPF ratio value decreased to $1.78 \pm 0.05$ during the application of PACAP-38 $(P>0.05)$ and recovered completely during washout $(1.9 \pm 0.02)$.

term depression (LTD), as it could be elicited in the presence of 2-amino-5-phosphonovalerate (APV) or in the presence of inhibitors of cAMP- or $\mathrm{Ca}^{2+}$-dependent protein kinases (Kondo et al. 1997). Our preliminary data confirmed that $1 \mu \mathrm{M}$ PACAP-38 induces LTD of fEPSPs (not shown). In addition, we showed that atropine did not block $1 \mu \mathrm{M}$ PACAP-38-induced depression (not shown). These differential concentration-dependent PACAP-38 effects suggest that the mechanism involved in PACAP-38-induced enhancement of CA1 fEPSP responses is distinct from those underlying PACAP-38-induced depression and that these responses might be mediated by different sites of action of this peptide. Our primary finding is that a lower dose of PACAP-38 (0.05 nM) induced a long-lasting enhancement of Schaffer collateral-commissural CA1 synaptic strength, which was similar to the long-term facilitation of hippocampal synaptic transmission that has been observed in LTP. LTP is a long-lasting increase in the CA1 postsynaptic responses that results from a brief train of tetanic stimulation of afferent fibers, and it is considered to be a prolonged form of activity-dependent synaptic plasticity related to learning and memory (Bliss and Lomo 1973; Chen and Tonegawa 1997; Abel and Kandel 1998). We therefore investigated the possibility of a common mechanism downstream from the PACAP-38-induced enhancement and the tetanus-induced LTP. If the mechanisms were separate phenomena, it might be expected that they should be additive. In these experiments, PACAP-38 application caused only a transient increase in the evoked responses after the LTP mechanism was saturated by three successive trains of HFS. This different time course of PACAP-38 action after the saturation of LTP compared with the baseline evoked activity indicates that PACAP-38 and afferent tetanic stimulation share, in part, a common mechanism for induction of enhancement of the CA1 synaptic responses. Masuo et al. (1993) showed that PACAP-38 (12 pM, 120 pM) increases the spontaneous release of ACh from the cholinergic terminals in the rat dorsal hippocampus in a dose-dependent manner. The hippocampus receives massive cholinergic innervation from the medial septum-diagonal band (Val-

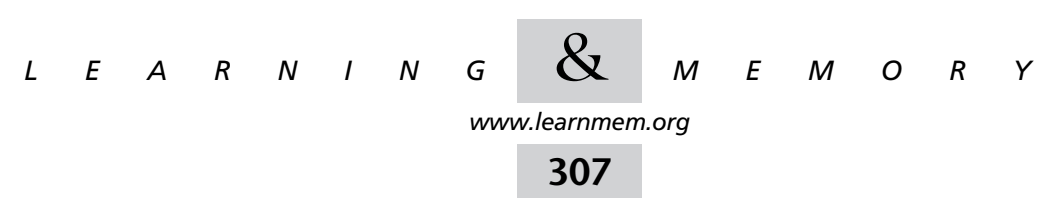




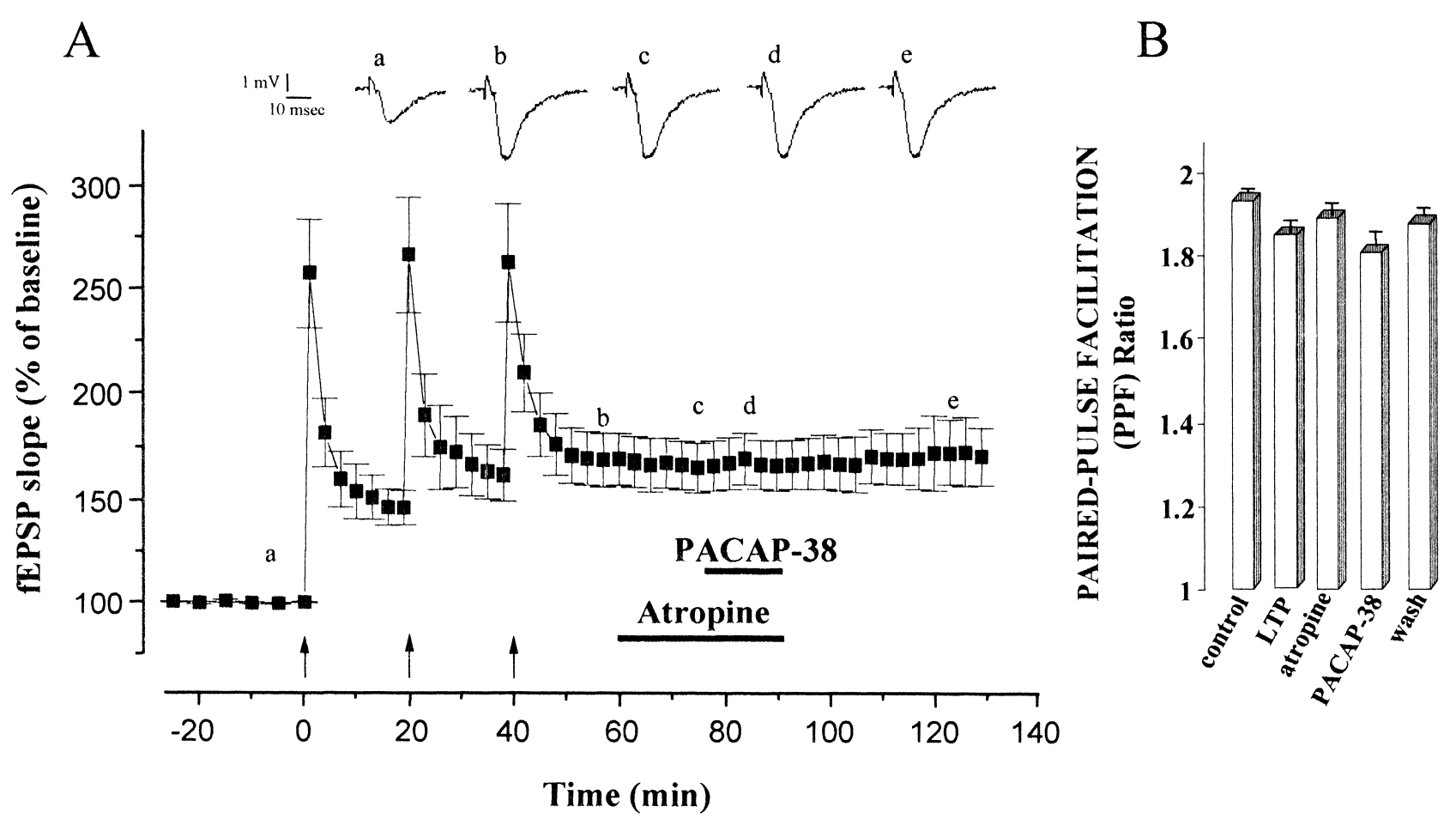

Figure 5 Blockade by atropine of pituitary adenylate cyclase-activating polypeptide-38 (PACAP-38)-induced enhancement of CA1 excitatory postsynaptic field potentials (fEPSP) following long-term potentiation (LTP) saturation by repeated tetani. ( $A$ ) The potentiation of the mean fEPSP slope recorded after the series of high frequency stimulation (HFS) was $168.3 \pm 12.4 \%(n=12, P<0.001) .1 \mu \mathrm{M}$ atropine applied after LTP saturation had no effect on fEPSP slope (mean fEPSP slope $165.4 \pm 11.6, P>0.05$ ) but when applied with $0.05 \mathrm{nM}$ PACAP-38, atropine completely blocked the PACAP-38-induced enhancement (at $10 \mathrm{~min}$ after coapplication of atropine and PACAP-38 the mean fEPSP slope was $166.4 \pm 11.2, n=12$, compared with PACAP-38-induced enhancement of fEPSP slope $203.7 \pm 13.1 \%, n=8$ ). The traces show the fEPSP (average of five single sweeps) recorded from a representative slice at the times marked on the graph: At the control period (a); after tetanic LTP saturation (b); after atropine application (c); during coapplication of atropine and PACAP-38 (d); and on washout. (B) mean paired-pulse facilitation (PPF) ratio at the time points marked in $A(a, b, c, d, e)$. After LTP saturation, atropine did not alter the PPF ratio of the fEPSP slope. PACAP-38 induced a slight decrease of the PPF ratio from $1.89 \pm 0.05$ to $1.81 \pm 0.08(P>0.05)$ and during washout of the peptide the mean PPF ratio returned to $1.87 \pm 0.06$.

entino and Dingledine 1981; Krnjevic and Ropert 1982; Frotscher and Léranth 1985; Hepler et al. 1985; Madison et al. 1987). ACh is known to evoke multiple effects in hippocampal neurons and the cholinergic influences on the evoked responses are strongly dependent on the sites of application (Bernardo and Prince 1982; Cherubini et al. 1982; Frotscher and Léranth 1985; Madison et al. 1987; Benson et al. 1988; Chen and Tonegawa 1997). Several lines of evidence show that the cholinergic system plays a role in facilitating plastic changes at Schaffer collateral-commissural-CA1 synapses in accordance with the well-known memory-facilitating action of ACh (Markram and Segal 1990; Auerbach and Segal 1994). Specifically, ACh has an excitatory postsynaptic muscarinic effect on the CA1 pyramidal neurons by inducing a long-lasting enhancement of evoked responses (Marchi and Raitieri 1989; Markram and Segal 1990; Auerbach and Segal 1994; Shimoshine et al. 1997). Recently, it has been shown that this ACh-induced, longlasting enhancement (LTPm) is prevented by atropine, a muscarinic receptor antagonist (Marchi and Raitieri 1989;
Blitzer et al. 1990; Markram and Segal 1990; Shimoshine et al. 1997). The molecular mechanism of this long-lasting facilitation of EPSPs is still under debate. One possibility is that LTPm is correlated with an increase in postsynaptic excitability (Krnjevic et al. 1981; Bernardo and Prince 1982; Krnjevic and Ropert 1982; Madison et al. 1987; Benson et al. 1988) associated with an increase in membrane resistance that is mediated by a selective inactivation of the $\mathrm{K}^{+}$channel (Madison et al. 1987; Markram and Segal 1990). Alternatively, LTPm could be attributable to an increase in the $\mathrm{Ca}^{2+}$ component of the $N$-methyl-D-aspartate (NMDA) response or by the activation of second messenger systems, which regulate intracellular $\mathrm{Ca}^{2+}$, which, in turn, modifies the NMDA response (Madison et al. 1987; Auerbach and Segal 1994; Markram and Segal 1990; Cormier et al. 1993; Huang and Malenka 1993). In either event, it has been shown that cholinergic agonist CCh had no effect when administered after the LTP mechanism had been saturated by repeated tetani. This evidence indicates that tetanus-induced potentiation and LTPm share a common mechanism

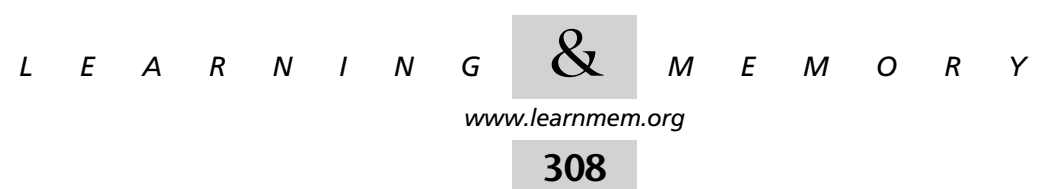


and provide a direct link between ACh and mechanisms of synaptic plasticity (Auerbach and Segal 1994,1996). To investigate the possible involvement of the cholinergic system in PACAP-38 action, we tested the effects of atropine. It is interesting that atropine blocked the facilitator effects on the fEPSP produced by PACAP-38 application on basal synaptic transmission and after LTP saturation. These data suggest that fEPSP facilitation induced by PACAP-38 might be correlated with an increase in ACh release from the septohippocampal terminals through the activation of muscarinic receptors. This might lead to postsynaptic regulation of NMDA responses, which are mediated by muscarinic receptors. We cannot exclude the possibility that the facilitator action of PACAP-38 might be a synergistic effect that is attributable to the cross-talk among the complex biochemical pathways by the combined activation of PACAP receptors and muscarinic receptors. In addition, this may explain the different time course of PACAP-38-induced enhancement during baseline condition and during activity-dependent LTP. In fact, electrophysiological studies have recently shown a dose-dependent potentiation of NMDA currents by PACAP-38 (10-30 nM) through a cAMP intracellular messenger (Wu and Dun 1997). Liu and Madsen (1997) provided the first detailed description of PACAP-38 (0.5-2 nM) acting as a direct modulator of NMDA receptors through the glycine coagonist site. In addition, stimulatory glutamatergic effects of PACAP-38 and other members of the peptide family also have been reported (Martin et al. 1995, Stella and Magistretti 1996; Wu and Dun 1997). In future experiments, to investigate the involvement of NMDA-receptor activation in the PACAP-38 actions, we will test the effect of APV on the PACAP-38-induced potentiation. In conclusion, this work has clearly shown that PACAP-38 enhances the CA1 synaptic strength and that this effect is mediated by the muscarinic cholinergic receptors. This PACAP-38 action might represent an interesting mechanism for potentiating the processes of learning and memory in the mammalian nervous system.

\section{MATERIALS AND METHODS}

The experiments were performed on transverse hippocampal slices $(400 \mu \mathrm{m})$ obtained from Wistar rats $(100-180 \mathrm{~g})$. We prepared hippocampal slices as described previously (Berretta et al. 1990). Briefly, the animals were anesthetized with halothane (3\% in air) and then decapitated. The brain was rapidly excised and cut using the vibroslicer (Campden Instruments Ltd.). Slices were stored at room temperature for at least $60 \mathrm{~min}$ in artificial cerebrospinal fluid (ACSF) of the following composition: $\mathrm{NaCl}, 130 \mathrm{mM}$; $\mathrm{KCl}, 3.5 \mathrm{mM}$; $\mathrm{NaH}_{2} \mathrm{PO}_{4}, 1.25 \mathrm{nM} ; \mathrm{MgSO}_{4}, 1.5 \mathrm{nM} ; \mathrm{CaCl}_{2}, 2 \mathrm{nM}$; $\mathrm{NaHCO}_{3}, 24 \mathrm{nM}$; glucose, $10 \mathrm{nM}$. The rats were then gassed with a $95 \% \mathrm{O}_{2}-5 \% \mathrm{CO}_{2}$ gas mixture, kept constantly at $\mathrm{pH} 7.4$. The slices were then transferred to a submersion recording chamber and perfused with ACSF at a rate of $2 \mathrm{ml} / \mathrm{min}$ at $30-32^{\circ} \mathrm{C}$. fEPSPs were recorded extracellularly from the apical dendritic layer of CA1 (stratum radiatum) with a glass micropipette (2-5M $\Omega$ ) filled with ACSF.
The signals were amplified and filtered (DC-3KHz) using an amplifier (Extracellular Amplifier BM 622). The data were stored on a PC for analysis using software developed with LABVIEW (National Instruments). Bipolar electrodes (SNEX-200, Rhodes Medical Instruments) were used for stimulation of Schaffer collateral-commissural afferent fibers. The intensity of the test stimulus, delivered at 0.033 $\mathrm{Hz}$, was adjusted for each slice so that the fEPSP was equal to approximately $50 \%$ of the maximum amplitude of the fEPSP. The saturation of LTP was induced by successive trains of high frequency stimulation (HFS; $100 \mathrm{~Hz}$ for $1 \mathrm{sec}$, three trains at $20 \mathrm{~min}$ intervals) at the same intensity as the test stimulus until no additional potentiation was elicited. PPF was examined in each slice using a 40-msec interpulse interval as previously described (Dobrunz and Stevens 1997). PPF is a transient increase in synaptic efficacy that is caused by the accumulation of residual $\mathrm{Ca}^{2+}$ within the presynaptic terminals following the initial stimulus pulse of a two-stimulation protocol, when the second stimulus follows shortly (20-200 msec) after the first stimulus (Voronin and Kuhnt1990; Andreasen and Hablitz 1994; Dobrunz and Stevens 1997; Schlulz 1997). Only the slices in which the elicited fEPSPs were constant for 20-30 min were used in this study. Atropine, when present, was applied in the bath for 10-15 min before the application of PACAP-38 in the same solution, and then both were removed. PACAP-38 was dissolved in 5\% Acetic acid ( $\mathrm{ACOH})$ then added to ACSF and applied for $10 \mathrm{~min}$ (we observed no effects of this $\mathrm{AcOH}$ concentration on synaptic transmission). Atropine was dissolved directly in ACSF. We averaged the evoked responses from five sweeps and measured the amplitude and slope of fEPSP. Pairedpulse data were normalized to determine the relative amount of facilitation for each slice. This was done by expressing the data as the ratio of the second response with respect to the first response. Compiled data were expressed as mean \pm standard error of the mean (S.E.M.). Statistical analysis was performed using a one-factor, one-way analysis of variance (ANOVA) with repeated measures; when appropriate, this was followed by the Fisher's post hoc test. Statistical significance was set at the $P<0.05$ level.

\section{ACKNOWLEDGMENTS}

We thank Dr. Thomas Nelson and Dr. Jeff Netzeband for valuable discussions, and Dr. Maurizio Cammalleri for graphics assistance. This research was supported in part by a 60\% Ministero dell'Universita e della Ricerca Scientifica Technologica (MURST) grant.

The publication costs of this article were defrayed in part by payment of page charges. This article must therefore be hereby marked "advertisement" in accordance with 18 USC section 1734 solely to indicate this fact.

\section{REFERENCES}

Abel, T. and Kandel, E. 1998. Positive and negative regulatory mechanisms that mediate long-term memory storage. Brain Res. Rev. 26: 360-378.

Andreasen, M. and Hablitz, J.J. 1994. Paired-pulse facilitation in the dentate gyrus: A patch-clamp study in rat hippocampus in vitro. $J$. Neurophysiol. 72: 326-336.

Arimura, A. 1992. Receptors for pituitary adenylate cyclase-activating polypeptide. Comparison with vasoactive intestinal peptide receptors. Trends Endocrinol. Metab. 3: 288-294

- 1998. Perspectives on pituitary adenylate cyclase-activating polypeptide (PACAP) in the neuroendrocrine, endocrine, and nervous system. Jpn. J. Physiol. 48: 301-331.

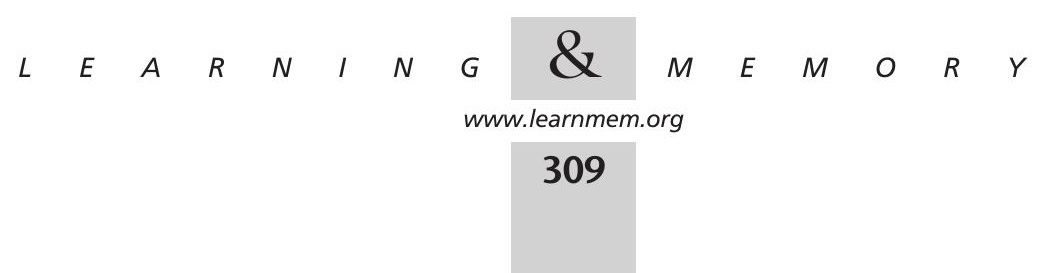


Arimura, A. and Shioda, S. 1995. Pituitary adenylate cyclase-activating polypeptide (PACAP) and its receptors: Neuroendocrine and endocrine interactions. Front. Neuroendocr. 16: 53-88.

Auerbach, J.M. and Segal, M. 1994. A novel cholinergic induction of long-term potentiation in rat hippocampus. J. Neurophysiol. 72: 2034-2040.

1996. Muscarinic receptors mediating depression and long-term potentiation in rat hippocampus. J. Neuropysiol. 492: 479-493.

Benson, D.M., Blitzer, R.L., and Landau, E.M. 1988. An analysis of the depolarization produced in guinea-pig hippocampus by cholinergic receptor stimulation. J. Physiol. 404: 479-496.

Bernardo, L.S. and Prince, D.A. 1982. Ionic mechanisms of cholinergic excitation in mammalian hippocampal pyramidal cells. Brain Res. 249: 333-344

Berretta, N., Berton, F., Bianchi, R., Capogna, M., Francesconi, W., and Brunelli, M. 1990. Effects of dopamine, D-1 and D-2 dopaminergic agonists on the excitability of hippocampal CA1 pyramidal cells in guinea pig. Exp. Brain Res. 83: 124-130.

Bliss, T.V.P. and Lomo, T. 1973. Long-lasting potentiation of synaptic transmission in the dentate area of anaesthetised rabbit following perforant path stimulation. J. Neurophysiol. 232: 331-356.

Blitzer, R.D., Gil, O., and Landau, E.M. 1990. Cholinergic stimulation enhances long-term potentiation in the CA1 region of rat hippocampus. Neurosci. Lett. 119: 207-210.

Brandner, C. and Schenk, F. 1998. Septal lesions impair the acquisition of cued place navigation task: Attentional or memory deficits? Neurobiol Learn. Mem. 69: 106-125.

Chen, C. and Tonegawa, S. 1997. Molecular genetic analysis of synaptic plasticity, activity-dependent neural development, learning and memory in mammalian brain. Ann. Rev. Neurosci. 20: 157-184.

Cherubini, E., Rovira, C., Ben-Ari, Y., and Padjen, A. 1982. Simultaneous recording of somatic and dendritic field potentials and combined microiontophoresis in the rat Ammon's horn in situ: Effects of GABA and acetylcholine. Neurosci. Lett. 31: 19-24.

Cormier, R.J., Mauk, M.D., and Kelly, P.T. 1993. Glutamate iontophoresis induces long-term potentiation in the absence of evoked presynaptic activity. Neuron 10: 907-919.

Dobrunz, L.E. and Stevens, C.F. 1997. Heterogeneity of release probability, facilitation, and depletion at central synapses. Neuron 18: 995-1008.

Feany, M.B. and Quinn, W.G. 1995. A neuropeptide gene defined by the Drosophila memory mutant amnesiac. Science 268: 869-873.

Frotscher, M. and Léranth, C. 1985. Cholinergic innervation of the rat hippocampus as revealed by choline actyltransferase immunocytochemistry: A combined light and electron microscopic study. J. Comp. Neurol. 239: 237-246.

Greengard, P., Jen, J., Nairn, A.C., and Stevens, C.F. 1991. Enhancement of the glutamate response by cAMP-dependent protein kinase in hippocampal neurons. Science 253: 1136-1138.

Hepler, D.J., Wenk, B.L., Cribbs, B.L., Olton D.S., and Coyle, J.T. 1985. Memory impairment following basal forebrain lesions. Brain Res. 346: 8-14.

Huang, Y. and Malenka, R.C. 1993. Examination of TEA-induced synaptic enhancement in area CA1 of the hippocampus: The role of voltage-dependent $\mathrm{Ca}^{2+}$ channels in the induction of LTP. J. Neurosci. 13: $568-576$

Kondo, T., Tominaga, T., Ichikawa, M., and Iijima, T. 1997. Differential alteration of hippocampal synaptic strength induced by pituitary adenylate cyclase activating polypeptide-38 (PACAP-38). Neurosci. Lett. 221: 189-192.

Krnjevic, R.P., Reiffenstein, R.J., and Ropert, N. 1981. Disinhibitory action of acetylcholine in the rat hippocampus: Extracellular observations. Neuroscience 6: 2465-2474.

Krnjevic, R.P. and Ropert, N. 1982. Electrophysiological and pharmacological characteristics of facilitation of hippocampal population spikes by stimulation of the medial septum. Neuroscience 7: 2165-2183
Leech, C.A., Holz, G.G., and Habener, J.F. 1995. Pituitary adenylate cyclase-activating polypeptide induces the voltage-independent activation of inward membrane currents and elevation of intracellular calcium in HIT-T15 insulinoma cells. Endrocrinology 136: 1530-1536.

Liu G.J. and Madsen, B.W. 1997. PACAP-38 modulates activity of NMDA receptors in cultured chick cortical neurones. J. Neurophysiol. 78: 2231-2234.

Madison, D.V., Lancaster, B., and Nicoll, R.A. 1987. Voltage clamp analysis of cholinergic action in the hippocampus. J. of Neurosci. 7: 733-741.

Malenka, R.C and Nicoll, R.A. 1999. Long-term potentiation- A decade of progress? Science 285: 1870-1874.

Marchi, M. and Raitieri, M. 1989. Interaction acetylcholine-glutamate in rat hippocampus: Involvement of two subtypes of M-2 muscarinic receptor. J. Pharmacol. Exp. Ther. 248: 1255-1260.

Margiotta, J.F. and Pardi, D. 1995. Pituitary Adenylate Cyclase-Activating Polypeptide type I receptors mediate cyclic AMP-dependent enhancement of neuronal acetylcholine sensitivity. Mol. Pharmacol., 48: 63-71.

Markram, H. and Segal, M. 1990. Long-lasting facilitation of excitatory postsynaptic potentials in the rat hippocampus by acetylcholine. $J$. Physiol. 427: 381-393.

Martin, J.-L., Gasser, D., and Magistretti, P.J. 1995. Vasoactive intestinal peptide and pituitary adenylate cyclase-activating polypeptide potentiate $c$-fos expression induced by glutamate in cultured cortical neurones. J. Neurochem. 65: 1-9.

Masuo, Y., Matsumoto, Y., Tokito, F., Tsuda, M., and Fujino, M. 1993 Effects of vasoactive intestinal polypeptide (VIP) and pituitary adenylate cyclase activating polypeptide (PACAP) on the spontaneous release of acetylcholine from hippocampus by brain microdialysis Brain Res. 611: 207-215.

Masuo, Y., Ohtaki, T., Masuda, Y., and Fujino, M. 1992. Binding sites for pituitary adenylate cyclase activating polypeptide (PACAP): Comparison with vasoactive intestinal polypeptide (VIP) binding site localization in rat brain. Brain Res. 575: 113-123.

Matthews, D.A., Salvaterra, P.M., Crawford, G.D., Houser C.R., and Vaughn, J.E. 1987. An immunocytochemical study of choline acetyltransferase containing neurones and axon terminals in normal and partially deafferented hippocampal formation. Brain Res. 402: 30-43

Miyata, A., Arimura, A., Dahl, R.R., Minamino, N., Uehara, A., Jiang, L., Culler, M.D., and Coy, D.H. 1989. Isolation of a novel 38-residue hypothalamic polypeptide which stimulates adenylate cyclase in pituitary cells. Biochem. Biophys. Res. Commun. 164: 567-574.

Miyata, A., Jiang, L., Dahl, R.D., Kitada, C., Kubo, K., Fujino, M., Minamino, N., and Arimura, A. 1990. Isolation of a neuropeptide corresponding to the N-terminals 27 residues of the pituitary adenylate cyclase activating polypeptide with 38 residues (PACAP-38). Biochem. Biophys. Res. Commun. 170: 643-648.

Schlulz, P.E. 1997. Long term potentiation involves increase in the probability of neurotransmitter release. Proc. Natl. Acad. Sci. 94: 5888-5893.

Shimoshige, Y., Maeda, T., Kaneko, S., Akaike, A., and Satoh, M. 1997. Involvement of M2 receptor in an enhancement of long-term potentiation by carbachol in Schaffer collateral-CA1 synapses of hippocampal slices. Neurosci. Res. 27: 175-180.

Shioda, S., Shuto, Y., Somogyvari-Vigh, A., Legradi, G., Onda, H., Coy, D.H., Nakajo, S., and Arimura, A. 1997. Localization and gene expression of the receptor for pituitary adenylate cyclase-activating polypeptide in the rat brain. Neurosci. Res. 28: 345-354.

Siegelbaum, S.A. and Kandel, E.R. 1991. Learning-related synaptic plasticity: LTP and LTD. Curr. Opin. Neurobiol. 1: 113-120.

Sokolov, M.V. and Kleschevnikov, A.M. 1995. Atropine suppresses associative LTP in CA1 region of rat hippocampual slices. Brain Res. 672: 281-284

Spengler, D., Waeber, C., Pantaloni, C., Holsboer, F., Bockaert, J., Seeburg, P.H., and Journot, L. 1993. Differential signal transduction by five splice variants of the PACAP receptor. Nature 365: 170-175. 
Stella, N. and Magistretti, P.J. 1996. Vasoactive intestinal polypeptide (VIP) and pituitary adenylate cyclase activating polypeptide (PACAP) potentiate the glutamate-evoked release of arachidonic acid from mouse cortical neurones. J. Biol. Chem. 271: 23705-23710.

Valentino, R.J. and Dingledine, R. 1981. Presynaptic inhibitory effect of acetylcholine in the hippocampus. J. Neurosci. 1: 784-792.

Voronin, L.L. and Kuhnt, U. 1990. Long-term potentiation affects facilitation ratio of EPSPs recorded from CA1 pyramidal cells in the guinea pig hippocampal slice. Neurosci. Res. Comm. 6: 149-155.

Wang, L.-Y, Salter, M.W., and Macdonald, J.F. 1991. Regulation of kainate receptors by cAMP-dependent protein kinase and phosphatases Science 253: 1132-1135.

Wu, S.Y. and Dun, N.J. 1997. Potentiation of NMDA currents by pituitary adenylate cyclase-activating polypeptide in neonatal rat sympathetic preganglionic neurones. J. Neurophysiol. 78: 1175-1179.

Zhong, Y. and Pena, L.A. 1995. A novel synaptic transmission mediated by a PACAP-like neuropeptide in Drosophila. Neuron 14: 527-536.

Received May 29, 2000; accepted in revised form August 8, 2000.

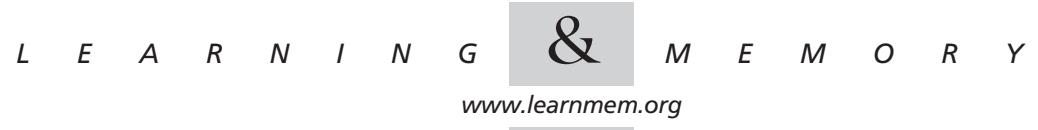




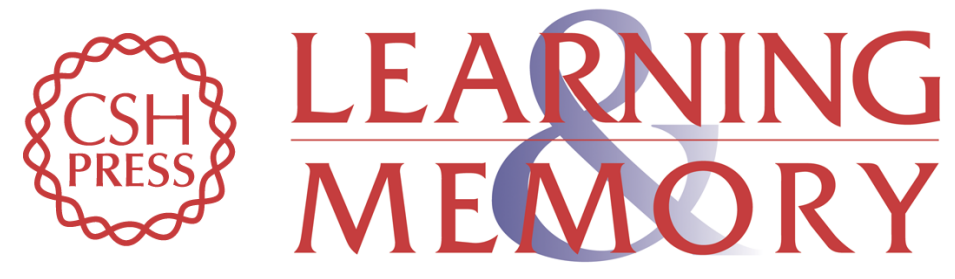

\section{PACAP-38 Enhances Excitatory Synaptic Transmission in the Rat Hippocampal CA1 Region}

Marisa Roberto and Marcello Brunelli

Learn. Mem. 2000, 7:

Access the most recent version at doi:10.1101//m.34200

References This article cites 49 articles, 10 of which can be accessed free at:

http://learnmem.cshlp.org/content/7/5/303.full.html\#ref-list-1

License

Email Alerting Receive free email alerts when new articles cite this article - sign up in the box at the Service top right corner of the article or click here. 